\title{
$\begin{array}{ll}\text { Research Square } & \text { Preprints are preliminary reports that have not undergone peer review. } \\ \text { They should not be considered conclusive, used to inform clinical practice, } & \text { or referenced by the media as validated information. }\end{array}$
}

\section{Microsurgical Treatment of Symptomatic Vestibular Schwannomas in Patients Under 40: Different Results Before and After Age of $\mathbf{3 0}$}

Luciano Mastronardi ( $\nabla$ mastro@tin.it)

San Filippo Neri Hospital https://orcid.org/0000-0003-0105-5786

Alberto Campione

San Filippo Neri Hospital

Guglielmo Cacciotti

San Filippo Neri Hospital

Ettore Carpineta

San Filippo Neri Hospital

Carlo Giacobbo Scavo

San Filippo Neri Hospital

Raffaelino Roperto

San Filippo Neri Hospital

Giovanni Stati

San Filippo Neri Hospital

Albert A. Sufianov

Federal Centre of Neurosurgery

Karl Schaller

University of Geneva Medical Center

\section{Research Article}

Keywords: vestibular schwannoma (VS), neurosurgery, microsurgery

Posted Date: May 14th, 2021

DOl: https://doi.org/10.21203/rs.3.rs-518788/v1

License: (c) (1) This work is licensed under a Creative Commons Attribution 4.0 International License. Read Full License

Version of Record: A version of this preprint was published at Neurosurgical Review on August 17th, 2021. See the published version at https://doi.org/10.1007/s10143-021-01603-4. 


\section{Abstract}

Background: In 10-15\% of cases of vestibular schwannoma (VS) age at diagnosis is 40 years or less. Little is known about the differences in natural history, surgical findings and postoperative outcomes of such younger patients as compared to those of greater age. Objectives : To analyze clinical and surgical and imaging data of a consecutive series of $n=50$ patients with unilateral sporadic VS, aged 40 years or younger - separated in a very young group (15-30 years) and a moderately young group (31-40 years). Study design: Retrospective case series

Methods: 50 consecutive patients under 40 years of age underwent microsurgical resection of unilateral sporadic VS via the retrosigmoid approach. The study cohort was subdivided into two groups according to the age range: Group A, age range 15-30 years ( $n=23$ patients) and Group B, age range 31-40 years $(\mathrm{n}=27$ patients). The adherence of VS capsule to surrounding nervous structures and the tendency of the tumors to bleed were evaluated by reviewing video records; the course of the FN in relation to the tumor's surface was assessed in each case. Microsurgical removal of tumor was classified as total $(T)$, near total (residual tumor volume $<5 \%$ ), subtotal (residual tumor volume $5-10 \%$ ) or partial (residual tumor volume $>10 \%)$.

Results: Mean tumor size of entire cohort was 2,53 (range: 0,6-5,8) cm: 2,84 cm in Group A and 2,36 cm in Group B ( $p=N S)$. Facial nerve course and position within the cerebellopontine angle did not differ significantly between the two groups. At 6-month follow-up, FN functional outcome was: HBI-II in 69,5\% in Group A, versus $96,3 \%$ in Group B ( $p<, 001)$. Hearing preservation was achieved in $60,0 \%$ of patients of Group A and in $58,3 \%$ of Group B ( $p=N S$ ). Total and near-total resection was feasible in $95,6 \%$ of cases of Group A and in $88,9 \%$ of Group B ( $p=N S$ ). Tumor capsule was tightly adherent to nervous structures in $69,6 \%$ patients of Group A and in $22,2 \%$ of Group B $(p<, 05)$. Significant bleeding was encountered in $56,5 \%$ of Group A tumors, and in $29,6 \%$ of Group B tumors $(p<, 01)$.

Conclusions: Microsurgery of VS in patients aged 40 or less is associated with good functional results, and with high rates of total and near total tumor removal. Patients $<30$ years of age have more adherent tumor capsules. Furthermore, their tumors exhibit a tendency to larger sizes, to hypervascularization, to profuse intraoperative bleeding and they present worse long-term functional FN results when compared to patients in their fourth decade of life. Our limited experience seems to suggest that a near total resection in very young VS patients with large tumors should be preferred in adherent and hypervascularized cases, in order to maximize resection and preserve function.

\section{Introduction}

Vestibular schwannoma (VS) is the most common tumor of cerebellopontine angle, accounting for 85 to $92 \%$ of tumors in that anatomical region. $[5,19,27,32,33,42]$ Clinical presentation correlates with the structures gradually and chronically compressed. Over the past 40 years incidence of VS has increased 
more than 10 times and mean age at diagnosis has increased from approximately 49 to 60 years. [8,28] Notwithstanding, in about $10-15 \%$ of cases age at diagnosis is $\leq 40$ years. $[8,28]$

Patient's age, symptoms, Koos grade [15], growth pattern and co-morbidities determine the treatment of choice among three options: watchful waiting (WW), radiation therapy (RT), and microsurgery.

$[27,32,33,42]$ The main aims of management of VS are: improving quality of life, preserving neurological functions, minimizing mortality and morbidity rates. The therapeutic strategy should also take into account the patient's own expectations from treatment, and the final approach is carefully individualized. $[5,19]$

We retrospectively analyzed clinical and surgical data of a consecutive series of 50 symptomatic patients with VS operated on at the age of 40 or younger, and compared outcomes, highlighting extent of tumor removal, postoperative nerve functions, and complications observed in patients in their second-third decade of life compared to those in their fourth one. Specifically, we analyzed whether surgical coplexity in terms of adherences and vascualrity differed between younger and older patients. We also tested whetehr tumor sizes differed with age.

\section{Methods}

\section{Patient population.}

We retrospectively reviewed 50 consecutive cases of unilateral VS aged 40 years or less, operated on at San Filippo Neri Regional/Community Hospital of Rome by the first Author (LM) between September 2010 and September 2019, out of 225 cases operated on in the same period. In relation to the hypothesis of a more aggressive behavior of VS in younger subjects, we splitted patients into two groups: patients $<30$ years (Group A) versus patients of 31-40 years of age (Group B).

Only sporadic VS were considered. In 3 patients aging 20 years or less, family history, spinal MRI and ophtalmological evaluation were considered in order to exclude possible NF2; genetic testing was done in a young lady aging 15 years at diagnosis of unilateral VS and it was negative. Clinical data such as patient's age, sex, presenting symptoms, and tumor size were recorded. Preoperative neuroimaging studies included temporal bone computed-tomography (CT) and gadolinium enhanced magnetic resonance imaging (MRI) in all.

According to international criteria, tumor size was categorized measuring the largest extrameatal tumor diameter on post-contrast axial MRI. [14] According to Koos et al. [15], tumors were classified in four grades, in relation to maximal diameter. All patients with Koos Grade I and II VS were followed for a minimum of two years, and only tumors showing progressive growth of $2 \mathrm{~mm} /$ year or more in the maximum diameter on MRI scans were selected for microsurgical treatment. Two patients (group B) received Stereotactic Radiosurgery (SRS) before surgery. 
Microsurgery via a standard retrosigmoid approach was performed in all cases. The course of the FN was classified into four different patterns: anterior (ventral) surface of the tumor (ANT), anterior-inferior (Al), anterior-superior (AS), and dorsal (D). [16,30]

Preoperative audio-vestibular evaluation included: pure tone audiometry, speech audiometry and auditory brainstem responses (ABR). Hearing level $(\mathrm{HL})$ was determined according to the American Academy of Otolaryngology-Head and Neck Surgery (AAO-HNS) classification. [4] HL Class A (Speech discrimination score $>70 \%)$ and Class B (50-70\%) were categorized as socially useful: in these cases, especially in Koos $\mathrm{I}-\mathrm{II}$ VS, hearing preservation (HP) was always attempted. Class $\mathrm{C}$ corresponds to a Speech discrimination score $<50 \%$ and Class $D$ to complete hearing loss. [4]

We classified the extent of tumor removal as total (T), near total (NT: linear millimetric residual tumor), subtotal (ST: residual tumor volume $<10 \%$ ), and partial (P: residual tumor volume $>10 \%)$. Extent of resection was evaluated by a consensus from comparison of pre- and postoperative MRI performed by one coauthor of the neurosurgical staff and one neuroradiologist who were blinded to outcome. In a second stage, their evaluation was compared with the assessment in surgical report.

\section{Clinical follow-up}

Clinical and radiological follow-up was scheduled six months after operation and once a year thereafter;

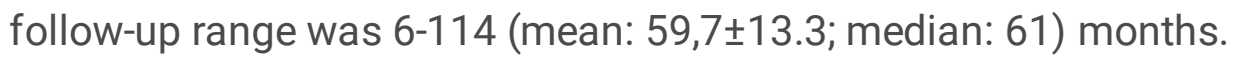

Hearing preservation (HP) and long-term FN outcome (according to House-Brackmann grades) [11] was performed six months after operation and at final follow-up (March 31, 2020). HB grades I-II were categorized favorable outcome, grade III, IV and V unfavorable.

Perioperative findings and surgical outcome of Group A and B were compared, with particular focus on intraoperative FN location and outcome, postoperative HP, and extent of surgical removal. In addition to that, adherences of tumor capsule and tendency to bleed were evaluated. Transient and permanent complications, and rates for surgical and mortality were recorded as well.

\section{Intra-operative procedures: FN and Cochlear nerve preservation}

\section{IONM of FN and stimulation parameters}

FN electromyography (EMG) was intraoperatively used (Nimbus i-Care-100, Newmedic, Hemodia, Labege, France), with electrodes inserted in orbicularis oris and orbicularis oculi muscles. FN stimulation was performed with monopolar stimulator, from $2 \mathrm{mAmp}$ (on the tumor surface) to $0,3-0,01 \mathrm{mAmp}$ (on the nerve), for confirmation of FN function. Final stimulation of FN was always performed both proximally (at the level of brainstem) and distally (in the IAC) and the power of stimulation was recorded.

Distal and proximal FN was was always exposed with IONM feedback. The stimulation threshold at the end of operation was always reported. In order to respect a balance between preservation of functions 
and maximal resection, when the threshold reached $0,5 \mathrm{mAmp}$ ore more, especially in VS without a clear dissection plane, we decided to stop tumor removal.

\section{IONM of cochlear nerve and stimulation parameters}

Patients with preoperative hearing Class A-B received ABR audiometry (Nicolet Viking III, Viasys HealthCare, Madison USA/Hochberg Germany) before surgery. ABR were evoked with LS-CE-Chirp ${ }^{\circledR}$ stimuli (Interacoustics Eclipse-EP15-ABR-System, Denmark), by means subdermal nedlees or surface electrodes placed at vertex $(\mathrm{Cz})$ and on earlobes $(\mathrm{A} 1, \mathrm{~A} 2)$.

Sound-pressure ranged between $60 \mathrm{~dB}-100 \mathrm{dBHL}$, producing clear monitorable waves. Controlateral ear was masked by $50 \mathrm{dBHL}$ white noise. Time analysis was about $40-60$ seconds per sweep with Click and 10-15 seconds with LS-CE-Chirp.

On surgeon's request, one or multiple series of 400-1200 acoustic stimuli were applied.

\section{Retrosigmoid approach}

All operations were performed by RS approach in lateral position. A slightly curved $5-6 \mathrm{~cm}$ skin incision behind the ear, $1 \mathrm{~cm}$ behind the mastoid, was performed, including the preparation of a free pericranial flap for dural closure. Then, the lateral occipital bone, including the superior and inferior nuchal lines, was exposed and an app. $3 \times 3 \mathrm{~cm}$ craniotomy with exposure of sigmoid and transverse sinuses was performed. The dura was opened in semicircular shape. By sharp opening of the lateral cerebellomedullary cistern, cerebrospinal fluid (CSF) was aspirated, facilitating gentle cerebellar retraction.

IAC opening was performed at very early stage: by cutting the dura covering the periphery of the IAC. Then, ICA-unroofing was achieved with a $4 \mathrm{~mm}$ extracoarse diamond burr or with the Sonopet ${ }^{\circledR}$ Ultrasonic Aspirator (Stryker, Kalamazoo, MI) with dedicated bone tips. Under gentle cerebellar retraction, the tumor capsule was exposed and the course of the FN was determined with monopolar stimulation.

A "V-cut" on the dorsal surface of tumor between the superior and inferior vestibular nerves was performed with laser fiber or microscissors, followed by tumor debulking by use of low-energy Sonopet ${ }^{\circledR}$ Ultrasonic Aspirator. Then, with microsurgical instruments, the tumor capsule was dissected from cranial nerves during continuous facial and cochlear nerve monitoring. Lastly, the tumor capsule was removed piece by piece with microscissors. Tumor excision near the fundus was performed under endoscopic visualization, by blunt and sharp dissection. In case of strong adhesions millimetric fragments of the capsule was left.

For preserving cranial nerve functions, oxidized cellulose, surgical patties, and saline irrigation with steroids were used. At the end, the wall of IAC was covered with bone wax. After accurate hemostasis, tight dural closure using the pericranial flap, haemostatics, and sealants was performed and the autologous bone flap was fixed with miniscrews. 
For assessing adherence of capsule to FN and brainstem and the tendency of tumor to bleed, two coauthors blinded to patient identity, surgical report and outcome graded adherences and tendency to bleed subjectively as minor or major adherences and minor or major tendency to bleed.

VS without clear perineural dissection plane from nervous structures (FN and brainstem) were classified as "major adherences". Unfortunately, there is no scale for the degree of adherences: therefore, minor adhesions were defined as cases where the facial nerve could be separated from the tumor comparatively easily with a microdissector, and major adhesions were defined as those that were difficult to separate, requiring sharp dissection with microscissors. In cases where adhesions where too tight to ensure safe total resection in the surgeons estimation, a sub- total resection was selected.

VS with unusual and redundant vascular architecture, which tended to profuse intratumoral bleeding during debulking and dissection due to multiple small and pathological vessels, were categorized as hypervascular. The possible high-bleeding behaviour of tumor was suspected in the preoperative T2weighted MRI images when multiple "serpiginous" flow voids, representing large feeders and draining veins, within the mass were observed.

\section{Statistical analysis}

Chi-square test for categorical variables and t-test for continuous variables were adopted, using MS Excel software (Microsoft Corporation, Redmond, WA, USA). P-values $<, 05$ were considered significant and values $>, 05$ not significant (NS).

\section{Results}

Preoperative clinical and radiological characteristics of the study population are summarized in Table 1.

Patients were subdivided in two groups: Group A ( $n=23$; nine women, fourteen men), age range $15-30$ years and Group $B$ ( $n=27$; thirteen women, fourteen men), age range 31-40 years.

Mean age of entire population was 31,7 (15-40) years: 25,8 years in Group A and 36,8 years in Group B. Mean tumor size of entire series ( 225 cases) was $2,62 \mathrm{~cm}$ (range $0,6-5,8)$ versus $2,53 \mathrm{~cm}$ of patients under $40(p=N S)$; it was $2,84 \mathrm{~cm}$ in Group A, $2,26 \mathrm{~cm}$ in Group $B(p=, 06)$. The mean diameter of VS in patients under-40 was significantly different in presence of adhesions and in bleeding tumors. In detail, VS with tight adherences of capsule to FN and/or brainstem had a mean diameter of 3,10 cm versus 2,01 $\mathrm{cm}$ of non-adherent $(p<, 01)$. Hypervascular and high-bleeding VS had a mean diameter of $3,32 \mathrm{~cm}$ versus $1,79 \mathrm{~cm}$ of hypovascularized tumors $(\mathrm{p}<, 01)$.

Major clinical symptoms included hearing impairment, gait disturbances and facial paraesthesias. Among Group B, five had trigeminal nerve symptoms (18,5\%) versus two in Group A (8,7\%) (NS). In ten 
patients of Group A VS were left-sided and in $n=13$ right-sided, versus $n=13$ and $n=14$ in Group B, respectively.

Preoperative auditory assessment of Group A showed $n=8$ patients $(34,8 \%)$ with Grade $D$ hearing loss, $n=10(43,5 \%)$ grade $C$ hearing impairment, $n=4(17,4 \%)$ grade $B$, and one $(4,3 \%)$ had Grade $A$ hearing. In Group B, 6 patients $(22,2 \%)$ had Grade D hearing loss, $9(33,3 \%)$ grade $C$ impairment, $n=10(37 \%)$ grade $B$, and two $(7,5 \%)$ Class A hearing (NS).

Relationship between extent of surgical removal and age of patients is summarized in Table 2. The blind review of postoperative MRI performed by one member of our neurosurgical staff and one neuroradiologist was in accordance with the surgical reports except for 3 cases (NT removal for the surgeon and ST for reviewers). In the whole series, total removal was obtained in $n=40$ patients $(80,0 \%)$, near total in $n=6(12.0 \%)$, and subtotal in $n=4(8.0 \%)$. In Group A, T-NT resection was achieved in $95,6 \%$ of patients, in comparison to $88,9 \%$ of Group $B(p=N S)$. At median follow-up of 61 months, a recurrence/regrowth of residue was observed in 4 cases $(8,0 \%$ ) operated on with ST resection (1 Group $A$ and 3 Group $B)$ : in one of three recurrent patients of Group B a second surgery was necessary for large cystic transformation 4 years after the first operation. In the other 3 cases, the initial growth of tumor ceased at MRI controls performed once a year.

In accordance with the independent "blinded" opinion of the two reviewers, as for the entire cohort, the tumor capsule was tightly adherent to FN and/or brainstem in $n=22$ cases (44\%): 69,6\% of Group A and $22,2 \%$ of Group B $(p<, 05)$; among the 6 cases of Group B showing tight adhesion of capsule, 2 received preoperativer SRS. In detail, the adhesion of capsule to FN was at the level of the porus acusticus internus in $90,9 \%$ of patients (20 out 22 ).

In the whole series, $n=21$ VS (42,0\%) were highly vascularized and showed profuse intraoperative bleeding: $56,5 \%$ belonged to Group A and $29,6 \%$ to Group B $(p<, 01)$ (Table 3).

Hearing and FN results at final follow-up are summarized in Table 4. Intraoperative FN course and position in cerebellopontine angle in the entire series was: AS in 40,0\%, ANT in $24,0 \%$ and AI $36,0 \%$. In detail, Group A: AS 43,5\%, ANT 26,1\%, Al 30,4\%. In Group B rates were: AS 37,1\%, ANT 22,2\%, Al 40,7\% (NS).

At minimum 6-month follow-up, FN results were: $\mathrm{HBI} 74,0 \%$; HBII 10,0\%, HBIII $12 \%$ and HBIV 4,0\%. As regard the final stimulation of $\mathrm{FN}$ at the level of brainstem exit point, it was obtained with $0,3 \mathrm{mAmp}$ or less in patients with $\mathrm{HBI}-\mathrm{II}$ function, 0,3 and $0,5 \mathrm{mAmp}$ in patients $\mathrm{HBIII}$ function and $0,5 \mathrm{mAmp}$ or more in HBIV.

In detail, in Group A FN results were HBI-II in 69,5\%, HBIII 21,7\% and HBIV 8,7\%, whereas in Group B 96,3\%, one and zero, respectively $(\mathrm{p}<, 001)$. Therefore, patients in their fourth decade of life had a better long-term FN result: $96,3 \%$ of HBI-II function, compared to $69,5 \%$ of younger ones. 
HP was possible in $58,8 \%$ patients of the entire cohort with preoperative socially useful hearing: $60,0 \%$ of Group A and $58,3 \%$ of Group B (NS).

Mortality and major morbidity were not observed. Seven patients (14,0\%) experienced transient morbidity: two patients of Group B required additional surgery for superficial infection; two other patients of Group B and one patients of Group A had transient cerebrospinal fluid leakage, successfully treated with external lumbar drainage; two patients of Group A had diplopia (abducens nerve paralysis) lasting 3 and 4 months, respectively; one patient of Group A had a pneumonia, which resolved with antibiotic therapy.

\section{Discussion}

VS microsurgery requires a long learning curve and continuing refinements. [14,17,23,31] Recently, a combined approach of intented microsurgical STR followed by SRS, validated by EANO guidelines [9], showed clinical and functional outcomes comparable to those obtained with T/NT removal (GTR) $[36,37]$.

Analyzing the results of a systematic review and meta-analysis of 248 patients affected by VS ( 9 series), with a mean age of about 51 years (range 18-85), treated with this combined approach, Starnoni et al [36] reported a progression-free survival of 93,9\% (range 78-100), at a mean follow-up of 36,9 months, with necessity of "salvage" treatment (second STR or SRS) in about $5 \%$ of patients. In addition, the functional results were encouraging too: HBI-II FN function was obtained in $96,1 \%$ and HP in 59,9\% of patients. [34]

Recently, the EANS skull base section published a systematic review, meta-analysis and consensus statement on the surgical management of large VS [37]: they collected 43 series (4510 patients) of gross total resection (GTR) and 11 series (467 cases, with a mean follow-up of 47,7 months) of planned STR followed by SRS. In the GTR group the mean HBI-II FN result was $60,1 \%$ (range $30-84 \%$ ) and the mean HP rate $28,6 \%(2-56,2 \%)$, with a tumor control ranging from $90,9 \%$ to $100 \%$; in the STR+SRS group the mean HBI-II FN result was $91,1 \%(81-100 \%)$ and the mean HP of $61,2 \%$ (25-100\%), with a tumor control ranging from $79 \%$ to $100 \%)$. [37]

On considering patients affected by VS younger than 40 years, few data are available in the literature. Sughrue et al [38] reported a series of 204 patients younger than 40 at diagnosis: GTR was possible in $85 \%$ of patients with maximum diameter $<3 \mathrm{~cm}$ and in $63 \%$ of larger tumors $(p<, 001)$; freedom from any tumor growth was $89 \%$ after 10 years and $86 \%$ after 20 years. In their series, FN preservation at 6 months (76\%) and HP (68\%) were statistically better in small size group. [38] On the basis of their results, the authors concluded that microsurgery provides excellent long-term tumor control in patients younger than 40 years operated on for VS. [37] The main differences we observed between younger and older patients of our series were: tighter adhesion of tumor capsule to $F N$ and brainstem $(p<, 05)$ and more vascularized and bleeding VS $(p<, 01)$ in Group A (Table 3$)$, FN outcome better in Group B $(p<, 001)$. In particular, the age of patients resulted in statistically significant functional differences: patients in their fourth decade of life had a better long-term FN result $(96,3 \% \mathrm{HBI}-\mathrm{II}$ function), compared to younger ones $(69,5 \%)$ (Table 4$)$. 
It is not clear why VS diagnosed in the second and third decade of life have a different behavior and outcome in comparison to those of patients in the fourth decade of life, given that all patients were operated in the same surgical setting and by the same surgeon. The overall favorable results are however in line with a previously published series of VS patients $<40$ years of age, although those authors did not establish various age groups. [38]

\section{Functional FN results.}

Although great emphasis is currently placed on preserving nerve functions after VS resection, FN injury still represents a relatively common postsurgical complication. Even when careful FN dissection is performed, an anatomically intact nerve does not necessarily predict normal function. Despite anatomical knowledge and experience, finding its proximal terminus may be difficult especially in large tumors. With the aim to preserve the nerve functions and in accordance with several Authors [14,17,23,29,31,34], in our practice we adopt the following steps: (1) intracapsular tumor debulking; (2) identification of FN and, in small tumors, cochlear nerve by means of IONM; (3) opening of IAC; (4) nerve dissection from tumor capsule, trying to preserve the arachnoid plane; (5) bimanual dissection of tumor capsule from FN and, when possible, cochlear nerve.

Troude et al. [40] analyzed the predictive factors for short-term and long-term FN function after VS resection by translabyrinthine or retrosigmoid approach. At discharge and at 1-month follow up FN function was best anticipated by preoperative facial function, intraoperative cochlear preservation and extrameatal tumor diameter. Such association had already reported by Nutik et al [21], whose review of 108 cases reported that anatomic preservation of $\mathrm{FN}$ was inversely related to tumor size and improved as the series progressed, stressing the relevance of the surgeon's experience. When the nerve was anatomically preserved, satisfactory postoperative outcome was inversely related to tumor size. Chiluwal et al. [3] found that T1-T3a tumor extension (Hannover classification) was significantly associated with better functional outcome than T3b at 3-months follow up. In our series, tumor size conditioned the functional nerve outcome only in Group A: patients $<30$ years of age had larger tumors and a significantly worse FN outcome than Group B at 6 months after surgery (HBI-II rate: 69.5\% vs 96.3\%).

In the long term, FN function is best anticipated by postoperative early FN outcome, whereas previous surgeries negatively affect the outcome. [39] In univariate analyses, additional predictive factors evaluated by Troude et al [39] were surgeon's experience and tumor remnant volume: the extent of resection did not seem to condition FN outcome.

Controversial results have been described as planned less-than-total resection for FN preservation. This is a crucial point to maximize resection while preserving function and its equally relevant even for very young VS patients. [35,37,40,44] Reporting a series of 37 patients operated on for large VS, with a mean follow-up of 36 months, Schneider et al. [35] reported the better outcome for NT versus T resection in large VS. In particular, their patients treated with NT resection had $100 \% \mathrm{HBI}-\mathrm{II}$ FN functional outcome compared to $78 \%$ of those with T removal, without signicant risk of recurrence [35]. 
Zumofen et al. [44] reported a HBI-Il postoperative rate of $89 \%$, without need for salvage surgery, after Gamma Knife had been administered onto planned tumor residues. However, Iwai et al. [12] found that optimal FN outcome (postoperative HBI-II of 95\%) could be jeopardized by the need for salvage surgery after Gamma Knife in case of large tumor remnants (at least $6 \mathrm{~cm}^{3}$ ). Such findings underline that radiosurgery could represent a complement to microsurgery [40], even if surgical removal should be attempted with the objective of maximal safe tumor eradication.

\section{Large and bleeding VSs. Adherence of capsule.}

According to Peris-Celda et al. [25], VS of younger patients are significantly larger than those of olders $(p<, 001)$, suggesting a more aggressive biology not yet completely understood. In their study the authors found that $>17 \%$ of 1304 VS had a tumor size $>3 \mathrm{~cm}$ and $>7 \%$ over $4 \mathrm{~cm}$. In addition, they observed a statistically significant difference of mean age at diagnosis: 52,3 years for $V S<4$ cm versus 42,4 years for larger ones $(p<, 001)$. [25] In addition, large and hypervascularized VS represent a microsurgical challenge, especially if the capsule is adherent to nervous structures.

Angiogenesis is fundamental for the growth of solid tumors, including schwannomas and the vascular endothelial growth factor (VEGF) is considered a major regulator [2]: its receptors have been identified on the surface of vascular endothelial cells [7] and its expression correlates with growth pattern of VS [2,26]. Uesaka et al [41] performed immunohistochemical studies for VEGF and VEGFR-1 mRNA on 36 VS confirming that, especially if recurrent, these tumors express high-level of these proteins. [40]

Adhesion to nervous structures seems to be related to downstream of effectors inducing synthesis of extracellular matrix metalloproteinase (MMP). [25] In particular, Moller et al. [20] observed that tumor concentration of matrix metalloproteinase-9 (MMP-9) correlates with VS growth pattern.

Carlson et al. [1] described genetic alterations observed in sporadic VS for evaluating if more clinically aggressive tumors show different genetic alterations compared to more indolent. Few studies attempted to profile genome-wide alterations in sporadic VS. In particular "two-hit" alterations of NF2 gene were identified in every tumor and were not present in peripheral blood, confirming that all events were somatic. [1] In our limited series, patients $<30$ years presented with larger, more adherent $(p<, 05)$ and more vascularized $(p<, 01)$ VS (Table 3 ) (Figures 1,2$)$, confirming the possibility of a biologically distinct tumor subtype that may have a phenotypically aggressive behavior.

Large tumor size often hinders safe and effective gross total resection and is associated to factors that negatively affect FN function, such as cystic consistency [6,18,22]. In Koos IV VS, negative FN outcome acts as confounding factor, concealing the primary cause of difficult dissection and resection.

Presumably, this happened in our series too: Group A carried worse postoperative FN function in large or giant tumor subgroup and showed significantly more adherent $(p<, 05)$ and more bleeding $(p<, 01)$ VS than patients over 30 (Group B). 
In the series reported by Tos et al. [39], HB I-Il function was achieved in $97 \%$ of medium-sized, $87 \%$ of large and $66 \%$ of giant tumors. Similar findings were reported by Ojemann [24] in 410 patients, although the size categories were different: normal FN function in $98 \%$ of small, $96 \%$ of medium sized $(1-1,9 \mathrm{~cm})$, $75 \%$ of medium large $(2-3 \mathrm{~cm}), 56 \%$ of large $(3-4 \mathrm{~cm})$ and $56 \%$ of giant VS $(>4 \mathrm{~cm})$. In their cohort of 45 large VS, Hoshide et al. [10] reported $83 \% \mathrm{HBI}-\mathrm{II}$ rate after total or near-total resection. The results of our series are in line with such features (T-NT in $92 \%$ and HBI-II FN function in $84 \%$ ). We agree with Schneider et al. [35], that a NT resection in very young VS patients with large tumors should be preferred to total removal, especially in adherent and hypervascularized cases, in order to maximize resection and preserving function.

\section{Conclusions}

Microsurgery of VS in patients aged $<40$ is associated with good functional results and high-rates of total or near-total removal of the tumor. Patients under 30 years of age seem to have more adherent, vascularized and larger VS, with worse long-term FN results than those in the fourth decade.

It is possible that these results correlate with specific molecular pathways. Studying occasional unilateral VS in younger patients will be of great interest in order to understand if these have peculiar biological characteristics that could represent new targets for possible neo-adjuvant targeted chemotherapy, to reduce tumor angiogenesis and, thus, intraoperative bleeding.

\section{Abbreviations}

AAO-HNS = American Academy of Otolaryngology - Head and Neck Surgery; ABR = auditory brainstem responses; $\mathrm{Al}=$ anterior and inferior; $\mathrm{ANT}=$ anterior; $\mathrm{AS}=$ anterior and superior; $\mathrm{c}$.e . contrast enhanced; $\mathrm{CT}=$ computed tomography; $\mathrm{D}=$ dorsal; $\mathrm{FN}=$ facial nerve; $\mathrm{GTR}=$ gross total removal; $\mathrm{HB}=$ HouseBrackmann; $\mathrm{HL}$ = hearing level; $\mathrm{HP}=$ hearing preservation; $\mathrm{IAC}=$ internal auditory canal; $\mathrm{MRI}=$ magnetic resonance imaging; NS = not significant; $\mathrm{RS}$ = retrosigmoid; $\mathrm{RT}$ = radiotherapy; $\mathrm{SRT}$ = subtotal removal; $\mathrm{SRS}=$ Stereotactic Radiosurgery; y.o. = year old; $\mathrm{VS}=$ vestibular schwannoma; $W W=$ watchful waiting .

\section{Declarations}

\section{FUNDING STATEMENT}

None (not applicable).

\section{CONFLICT OF INTEREST}

The authors declare that they have no known competing financial interests or personal relationships that could have appeared to influence the work reported in this paper.

\section{AVAILABILITY OF DATA AND MATERIAL (Data Transparency)}


Data available from the first Author on demand.

\section{CODE AVAILABILITY}

None (not applicable).

\section{ETHICS APPROVAL}

The study involves human participants: therefore, it has been reviewed and approved by local ethics committee of the Hospital. A written consent for scientific treatment of personal data was obtained from any patient before surgery. No potentially identifiable human images or data are presented in this study. All procedures performed in this study were in accordance with the ethical standards of the internal institutional ethics committee ("Comitato Etico Lazio 1" Members of ASLRoma1: Dr. Marco Tubaro, Dr. Teresa Calamia, Dr. Francesco Meo). A written consent was obtained from any patient included in the study.

\section{Consent to participate and Consent for publication}

All Co-Authors express formally their consent to participate to this study an to publish it, contributing in different ways.

\section{Author's individual contributions}

L.M.: study design, study conception, data analysis, manuscript writing

A.C.: data extraction, data analysis

C.G.S.: data extraction, data analysis, radiological measurement

E.C.: data extraction, data analysis, radiological measurement

G.C.: data extraction, data analysis, statistical analysis,

R.R.: data analysis, statistical analysis, critical review of the manuscript

A.A.S.: critical review of the manuscript, study supervision

K.S.: critical review of the manuscript, study supervision

\section{Disclosures:}

No funding has been received for this study.

The authors do not have any conflict of interest to be disclosed.

\section{References}


1. Carlson ML, Smadbeck JB, Link MJ, Klee EW, Vasmatzis G, Schimmenti LA (2018) Next Generation Sequencing of Sporadic Vestibular Schwannoma. Otology Neurotology 39(9):e860-e871

2. Caye-Thomasen P, Baandrup L, Jacobsen GK, Thomsen J, Stangerup SE (2003) Immunohistochemical demonstration of vascular endothelial growth factor in vestibular schwannomas correlates to tumor growth rate. Laryngoscope 113(12):2129-2134

3. Chiluwal AK, Rothman A, Svrakic M, Dehdashti AR (2018) Surgical outcome in smaller symptomatic vestibular schwannomas. Is there a role for surgery? Acta Neurochir (Wien) 160(11):2263-2275

4. Committee on Hearing and Equilibrium Guidelines for the Evaluation of Hearing Preservation in Acoustic Neuroma (Vestibular Schwannoma) (1995) Committee on Hearing and Equilibrium. Otolaryngology-Head Neck Surgery 113(3):179-180

5. Di leva A, Lee JM, Cusimano MD (2016) Handbook of skull base surgery. Thieme, New York

6. Eser Ocak P, Dogan I, Ocak U, Dinc C, Baskaya MK (2018) Facial nerve outcome and extent of resection in cystic versus solid vestibular schwannomas in radiosurgery era. Neurosurg Focus 44(3): E3

7. Ferrara N, Gerber H-P, LeCouter J (2003) The biology of VEGF and its receptors. Nat Med 9(6):669676

8. Gal TJ, Shinn J, Huang B (2010) Current epidemiology and management trends in acoustic neuroma. Otolaryngology-Head Neck Surgery 142(5):677-681

9. Goldbrunner R, Weller M, Regis J, Lund-Johansen M, Stavrinou P, Reuss D, Evans DG, Lefranc F, Sallabanda K, Falini A, Axon P, Sterkers O, Fariselli L, Wick W, Tonn JC (2019) EANO guide-line on the diagnosis and treatment of vestibular schwannoma. Neuro-Oncology. https://doi.org/10.1093/neuonc/noz153

10. Hoshide R, Faulkner H, Teo M, Teo C (2018) Keyhole retrosigmoid approach for large vestibular schwannomas: strategies to improve outcomes. Neurosurg Focus 44(3):E2

11. House JW, Brackmann DE (1985) Facial Nerve Grading System. Otolaryngology-Head Neck Surgery 93(2):146-147

12. Iwai Y, Ishibashi K, Watanabe Y, Uemura G, Yamanaka K (2015) Functional Preservation After Planned Partial Resection Followed by Gamma Knife Radiosurgery for Large Vestibular Schwannomas. World Neurosurg 84(2):292-300

13. Kanzaki J, Tos M, Sanna M, Moffat DA (2003) New and Modified Reporting Systems from the Consensus Meeting on Systems for Reporting Results in Vestibular Schwannoma. Otology Neurotology 24(4):642-649

14. Kohno M, Sato H, Sora S, Miwa H, Yokoyama M (2011) Is an Acoustic Neuroma an Epiarachnoid or Subarachnoid Tumor? Neurosurgery 68(4):1006-1017

15. Koos WT, Day JD, Matula C, Levy DI (1988) Neurotopographic considerations in the microsurgical treatment of small acoustic neurinomas. J Neurosurg 88(3):506-512 
16. Mastronardi L, Cacciotti G, Roperto R, Di Scipio E, Tonelli MP, Carpineta E (2016) Position and Course of Facial Nerve and Postoperative Facial Nerve Results in Vestibular Schwannoma Microsurgery. World Neurosurg 94:174-180

17. Mastronardi L, Fukushima T, Campione A (2019) Advances in Vestibular Schwannoma Microneurosurgery, 1 edn. Springer International Publishing, Cham

18. Mastronardi L, Gazzeri R, Barbieri FR, Roperto R, Cacciotti G, Sufianov A (2020) Postoperative functional preservation of facial nerve in cystic vestibular schwannoma. World Neurosurg, Apr 16. pii: S1878-8750(20)30725-7. doi: 10.1016/j.wneu.2020.04.018

19. Matthies C, Samii M, Krebs S (1997) Management of Vestibular Schwannomas (Acoustic Neuromas): Radiological Features in 202 Cases-Their Value for Diagnosis and Their Predictive Importance. Neurosurgery 40(3):469-482

20. Møller MN, Werther K, Nalla A, Stangerup SE, Thomsen J, Bøg-Hansen TC, Nielsen HJ, CayéThomasen $P$ (2010) Angiogenesis in vestibular schwannomas: Expression of extracellular matrix factors MMP-2, MMP-9, and TIMP-1. Laryngoscope 120(4):657-662

21. Nutik SL (1994) Facial nerve outcome after acoustic neuroma surgery. Surg Neurol 41(1):28-33

22. Nutik SL, Babb MJ (2001) Determinants of tumor size and growth in vestibular schwannomas. J Neurosurg 94(6):922-926

23. Ohata K, Tsuyuguchi N, Morino M, Takami T, Goto T, Hakuba A, Hara M (2002) A hypothesis of epiarachnoidal growth of vestibular schwannoma at the cerebello-pontine angle: surgical importance. J Postgrad Med 48(4):253-258

24. Ojemann RG (2001) Retrosigmoid approach to acoustic neuroma (vestibular schwannoma). Neurosurgery 48(3):553-55840.

25. Peris-Celda M, Graffeo CS, Perry A, Karezoudis P, Tombers NM, Carlson ML, Link MJ. (2019) Main Symptom that Led to Medical Evaluation and Diagnosis of Vestibular Schwannoma and PatientReported Tumor Size: Cross-sectional Study in 1,304 Patients.J Neurol Surg Part B, Skull base, 80(3):316-322.

26. Plotkin SR, Stemmer-Rachamimov AO, Barker FG, 2nd, Halpin C, Padera TP, Tyrrell A, Sorensen AG, Jain RK, di Tomaso E. (2009) Hearing improvement after bevacizumab in patients with neurofibromatosis type 2. N Engl J Med, 361(4):358-367.

27. Quiñones-Hinojosa A, Rincon-Torroella J. (2017) Video atlas of neurosurgery: contemporary tumor and skull base surgery. First edition. ed. Edinburgh; New York: Elsevier

28. Reznitsky M, Petersen MMBS, West N, Stangerup S-E, Cayé-Thomasen P. (2019) Epidemiology Of Vestibular Schwannomas - Prospective 40-Year Data From An Unselected National Cohort. Clin Epidemiol, 11:981-986.

29. Roosli C, Linthicum FH, Jr., Cureoglu S, Merchant SN. (2012) What is the site of origin of cochleovestibular schwannomas? Audiol Neurootol, 17(2):121-5.

30. Sameshima T, Morita A, Tanikawa R, Fukushima T, Friedman AH, Zenga F, Ducati A,Mastronardi L. (2013) Evaluation of variation in the course of the facial nerve, nerve adhesion to tumors,and 
postoperative facial palsy in acoustic neuroma. J Neurol Surg Part B, Skull Base, 74(1):39-43.

31. 3Sameshima T, Mastronardi L, Fukushima T. (2007) Fukushima's Microanatomy and Dissection of The Temporal Bone. Second ed. Raleigh, USA: AF-Neurovideo, Inc.

32. Samii M, Matthies C. (1997) Management of 1000 Vestibular Schwannomas (Acoustic Neuromas): The Facial Nerve-Preservation and Restitution of Function. Neurosurgery, 40(4):684-695.

33. Samii M, Matthies C. (1997) Management of 1000 Vestibular Schwannomas (Acoustic Neuromas): Surgical Management and Results with an Emphasis on Complications and How to Avoid Them. Neurosurgery, 40(1):11-23.

34. Sasaki T, Shono T, Hashiguchi K, Yoshida F, Suzuku SO. (2009) Histological considerations of the cleavage plane for preservation of facial and cochlear nerve functions in vestibular schwannoma surgery. Journal of Neurosurgery, 110(4):648 - 55

35. Schneider JR, Chiluwal AK, Arapi O, Kwan K, Dehdashti AR. (2020) Near total versus gross total resection of large vestibular schwannoma: facial nerve outcome. Oper Neurosurg,19(4): 414-421

36. Starnoni D, Daniel RT, Tuleasca C, George M, Levivier M, Messerer M. (2018) Systematic review and meta-analysis of the technique of subtotal resection and stereotactic radiosurgery for large vestibular schwannomas: a "nerve-centered" approach. Neurosurg Focus, Mar 44(3): E4

37. Starnoni D, Giammattei L, Cossu G, Link MJ, Roche PH, Chacko AG, Ohata K, Samii M,Suri A, Bruneau M, Cornelius JF, Cavallo L, Meling TR, Froelich S, Tatagiba M, Sufianov A, Paraskevopoulos D, Zazpe I, Berhouma M, Jouanneau E, Verheul JB, Tuleasca C, George M, Levivier M, Messerer M, Daniel RT. (2020) Surgical management for large vestibular schwannomas: a systematic review, metaanalysis,and consensus statement on behalf of the EANS skull base section. Acta Neurochir,162(11): 2595-2617

38. Sughrue ME, Kaur R, Rutkowski MJ, Kane AJ, Yang I, Pitts LH, Parsa AT. (2010)A critical Evaluation of vestibular schwannoma surgery for patients younger than 40 years age. Neurosurgery 67: 1646 1645

39. Tos M, Thomsen J, Harmsen A. (1988) Results of translabyrinthine removal of 300 acoustic neuromas related to tumour size. Acta Otolaryngol Suppl, 452:38-51.

40. Troude L, Boucekine M, Montava M, Lavieille JP, Regis JM, Roche PH. (2019) Predictive Factors of Early Postoperative and Long-Term Facial Nerve Function After Large Vestibular Schwannoma Surgery. World Neurosurg, 127:e599-e608

41. Uesaka T, Shono T, Suzuki SO, Nakamizo A, Niiro H, Mizoguchi M, Iwaki T, Sasaki T. (2007) Expression of VEGF and its receptor genes in intracranial schwannomas. J Neuro-Oncol, 83(3):259266.

42. Winn HR. (2017) Youmans and Winn neurological surgery. Seventh edition. ed. Philadelphia, PA: Elsevier

43. Wu H, Zhang L, Han D, Mao Y, Yang J, Wang Z, Jia W, Zhong P, Jia H. (2016) Summary and consensus in 7th International Conference on acoustic neuroma: An update for the management of sporadic acoustic neuromas. World J Otorhinolaryngol Head Neck Surge, 2(4):234-239. 
44. Zumofen DW, Guffi T, Epple C,Westermann B, Krähenbühl AK, Zabka S, Taub E, Bodmer D, Mariani L. (2018) Intended Near-Total Removal of Koos Grade IV Vestibular Schwannomas: Reconsidering the Treatment Paradigm. Neurosurgery, 82(2):202-210.Captions of Tables:

\section{Tables}

Table 1. Preoperative clinical and radiological characteristics of the study population 


\begin{tabular}{|c|c|c|c|c|}
\hline \multicolumn{2}{|c|}{ CHARACTERISTICS } & Group A & Group B & Chi- \\
\hline SEX & $\begin{array}{l}\text { Female } 22 \\
\text { Male } \quad 28\end{array}$ & $\begin{array}{l}9(39,1 \%) \\
14(60,9 \%)\end{array}$ & $\begin{array}{l}13(48,1 \%) \\
14(51,9 \%)\end{array}$ & NS \\
\hline \multicolumn{2}{|c|}{ MEAN AGE \pm SD (years) $31,7 \pm 11,3$} & $\begin{array}{c}25,8 \pm 9.1 \\
\text { (range } 15- \\
30)\end{array}$ & $\begin{array}{c}36,8 \pm 12.7 \\
\text { (range } 31- \\
40)\end{array}$ & \\
\hline SIDE & $\begin{array}{l}\text { Left } 23 \\
\text { Right } 27\end{array}$ & $\begin{array}{l}10 \\
13\end{array}$ & $\begin{array}{l}13 \\
14\end{array}$ & NS \\
\hline $\begin{array}{c}\text { MEAN } \\
\text { DIAMETER }(\mathrm{cm})\end{array}$ & $\begin{array}{c}\text { Entire cohort } 2,53 \mathrm{~cm} \text { (range: } 0,6 \\
-5,8 \mathrm{~cm})\end{array}$ & $2,84 \mathrm{~cm}$ & $2,26 \mathrm{~cm}$ & NS \\
\hline KOOS GRADE ${ }^{13}$ & $\begin{array}{cc}\text { Grade I } & 4 \\
\text { Grade II } & 16 \\
\text { Grade III } & 17 \\
\text { Grade IV } & 10\end{array}$ & $\begin{array}{c}2 \\
(8,7 \%) \\
5(21,7 \%) \\
9(39,1 \%) \\
7(30,5 \%)\end{array}$ & $\begin{array}{cl}2 & (7,5 \%) \\
11 & (40,8 \%) \\
8 & (29,6 \%) \\
3 & (11,1 \%)\end{array}$ & NS \\
\hline HEARING LOSS & $\begin{array}{l}\text { Grade A } 3 \\
\text { Grade B } 14 \\
\text { Grade C } 19 \\
\text { Grade D } 14\end{array}$ & $\begin{array}{c}1 \\
(4,3 \%) \\
4(17,4 \%) \\
10(43,5 \%) \\
8(34,8 \%)\end{array}$ & $\begin{array}{c}2(7,5 \%) \\
10 \\
(37,0 \%) \\
9(33,3 \%) \\
6(22,2 \%)\end{array}$ & NS \\
\hline $\begin{array}{l}\text { OTHER } \\
\text { SYMPTOMS }\end{array}$ & $\begin{array}{l}\text { VII cn deficit } \\
\text { V cn deficit } \\
\text { Ataxia } \\
\text { IX cn neuralgia } \\
\text { Hemiparesis }\end{array}$ & $\begin{array}{c}{ }^{3} \text { (HBII) }{ }^{2} \\
{ }^{2} \\
(8,7 \%) \\
2 \\
1 \\
1\end{array}$ & \begin{tabular}{c}
0 \\
\multicolumn{1}{c}{5} \\
$(18,5 \%)$ \\
4 \\
0 \\
0
\end{tabular} & NS \\
\hline
\end{tabular}

$\mathrm{SD}$ = standard deviation; $\mathrm{cn}$ = cranial nerve; NS = statistically not significant

Table 2. Relationship between extent of surgical removal and age. 


\begin{tabular}{|c|c|c|c|c|}
\hline Extent of resection & $\mathrm{T}$ & NT & ST & Chi-test \\
\hline$\overline{\text { re cohort (50 cases) }}$ & $40(80,0 \%)$ & $6(12,0 \%)$ & $4(8,0 \%)$ & \\
\hline roup A (23 cases) & $20(86,9 \%)$ & $2(8,7 \%)$ & $1(4,3 \%)$ & \\
\hline roup B (27 cases) & $20(74,1 \%)$ & $4(14,8 \%)$ & $3(11,1 \%)$ & \\
\hline
\end{tabular}

T=total; NT=near-total; ST=sub-total

Table 3. Adhesion of capsule and tendency of bleeding in the entire series and in the age-Groups.

\begin{tabular}{|c|c|c|c|c|}
\hline \multicolumn{2}{|l|}{ Entire series (50 cases) } & Group A & Group B & Chi- \\
\hline $\begin{array}{c}\text { Adhesion of capsule to } \mathrm{FN} \text { and/or } \\
\text { brainstem }\end{array}$ & $\begin{array}{c}\text { yes } 22 \\
(44,0 \%) \\
\text { no } 28 \\
(56,0 \%)\end{array}$ & $\begin{array}{r}16(69,6 \%) \\
7 \quad(30,4 \%)\end{array}$ & $\begin{array}{r}6(22,2 \%) \\
21(77,8 \%)\end{array}$ & $\mathrm{p}<, 05$ \\
\hline Highly vascularized (bleeding) tumors & $\begin{array}{c}\text { yes } 21 \\
(42,0 \%) \\
\text { no } 29 \\
(58,0 \%)\end{array}$ & $\begin{array}{l}13(56,5 \%) \\
10(43,5 \%)\end{array}$ & $\begin{array}{r}8(29,6 \%) \\
19(70,4 \%)\end{array}$ & $\mathrm{p}<, 01$ \\
\hline
\end{tabular}

Table 4. FN position and results and HP in the entire series and in the ageGroups. 


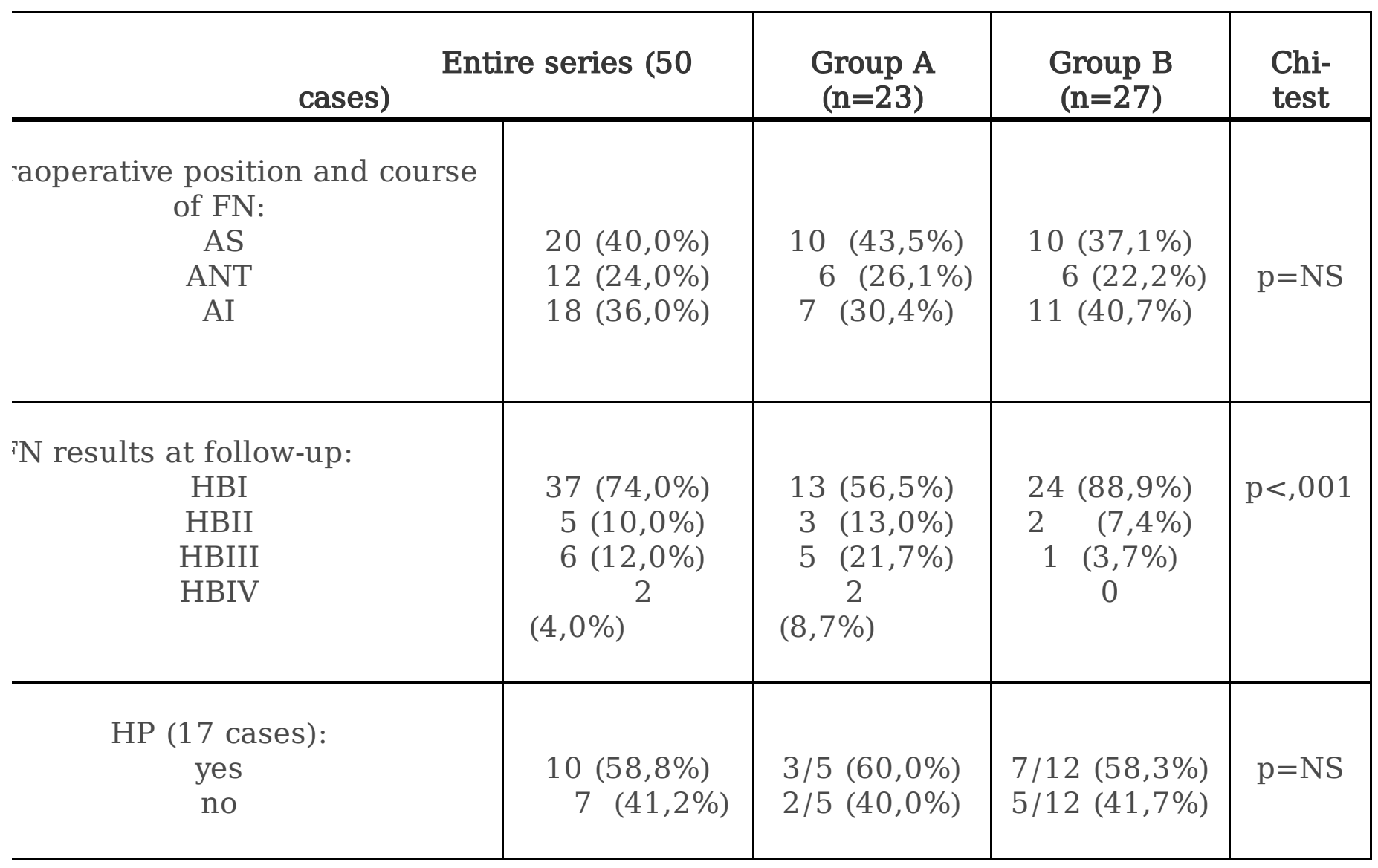

